\title{
Constraints on adaptive mutations in the codling moth Cydia pomonella (L.): measuring fitness trade-offs and natural selection
}

\author{
T Boivin ${ }^{1}$, JC Bouvier ${ }^{1}$, J Chadœuf ${ }^{2}$, D Beslay ${ }^{1}$ and B Sauphanor ${ }^{1}$ \\ ${ }^{1} U M R$ Ecologie des Invertébrés, INRA Site Agroparc, 84914 Avignon Cedex 09, France; ${ }^{2 B i o m e ́ t r i e, ~ I N R A ~ S i t e ~ A g r o p a r c, ~} 84914$ \\ Avignon Cedex 09, France
}

\begin{abstract}
Adaptive changes in populations encountering a new environment are often constrained by deleterious pleiotropic interactions with ancestral physiological functions. Evolutionary responses of populations can thus be limited by natural selection under fluctuating environmental conditions, if the adaptive mutations are associated with pleiotropic fitness costs. In this context, we have followed the evolution of the frequencies of insecticide-resistant mutants of Cydia pomonella when reintroduced into an untreated environment. The novel set of selective forces after removal of insecticide pressure led to the decline of the frequencies of resistant phenotypes over time, suggesting that the insecticideadapted genetic variants were selected against the absence of insecticide (with a selective coefficient estimated at 0.11 ). The selective coefficients were also estimated for both the
\end{abstract}

major cytochrome P450-dependent monooxygenase (MFO) and the minor glutathione $S$-transferase (GST) systems ( 0.17 and negligible, respectively), which have been previously shown to be involved in resistance. The involvement of metabolic systems acting both through xenobiotic detoxification and biosynthetic pathways of endogenous compounds may be central to explaining the deleterious physiological consequences resulting from pleiotropy of adaptive changes. The estimation of the magnitude of the fitness cost associated with insecticide resistance in C. pomonella suggests that resistance management strategies exclusively based on insecticide alternations would be unlikely to delay such a selection process.

Heredity (2003) 90, 107-113. doi:10.1038/sj.hdy.6800188

Keywords: adaptation; selection; fitness cost; pleiotropy; Cydia pomonella; resistance management

\section{Introduction}

Evolutionary responses of populations to a new environment involving mutations with a large phenotypic effect are likely to entail strong deleterious effects (Fisher, 1958). An adapted form may suffer a disadvantage relative to the ancestral form if, when reintroduced in its ancestral environment, the newly favoured character interferes with its ancestral function: a disadvantage regarded as the cost of pleiotropy (Uyenoyama, 1986). Limits to evolution by natural selection therefore arise if pleiotropic effects associated with novel mutations have negative impacts on other fitness-enhancing components (McNair, 1991). Quantitative genetic models provide critical informations on the genetic relationships that may evolve during adaptation in a new environment, but also translate the impact of the pleiotropic effects of newly selected genes on adapted genetic architectures in terms of fitness trade-offs (Holloway et al, 1990; Tienderen, 1997). The adaptation of numerous arthropod populations to environmental toxicity has evolved via the replacement of wild-type alleles with pesticideresistant alleles through strong directional selection (McKenzie and Batterham, 1994). Pesticide spraying in

Correspondence: T Boivin, UMR Ecologie des Invertébrés, INRA Site Agroparc, 84914 Avignon Cedex 09, France.

E-mail:boivin@avignon.inra.fr

Received 18 February 2002; accepted 3 August 2002 agro-ecosystems is generally regarded as a major shift in environmental conditions relative to the ancestral pesticide-free conditions. In this context, the theory of Fisher (1958) represents a suitable background for explaining the maintenance of polymorphism at the resistance loci, that is, resistance genes are rarely fixed, in natural pest populations (Coustau et al, 2001). Selection against resistance has been supported in field populations by a decrease of resistance frequencies in the absence of pesticide (Curtis et al, 1978; Lenormand et al, 1999). But because gene flows may also dilute resistance alleles in natural populations, resistance costs have been assessed in the laboratory by comparisons of life-history characters between susceptible and resistant strains (Roush and McKenzie, 1987; Carrière et al, 1994). It should be pointed out that this latter method requires that both susceptible and resistant strains share the same genetic background (Amin and White, 1984), and only a few studies have been conducted under such conditions. Another laboratory approach to assessing pleiotropic resistance costs consists in following changes in resistance frequencies in untreated population cages, in which resistant and susceptible alleles are segregating, over several generations (Minkoff and Wilson, 1992; Scott et al, 2000). This method favours the homogenization of genetic backgrounds by the creation of linkage equilibrium between coselected deleterious genes and each insecticide-resistant genotype, through recombinations occurring over generations in the laboratory populations. 
In the codling moth Cydia pomonella, both enhanced cytochrome P450-dependent monooxygenases (MFOs) and glutathione $S$-transferases (GSTs) have been independently shown to confer resistance to diflubenzuron (Sauphanor et al, 1997, 1998), the MFO system being regarded as a major mechanism involved in resistance to this compound relative to GST. Adaptation of this species to environmental toxicity through these two metabolic pathways has recently shown to be associated with pleiotropic costs with respect to reproduction and development (Boivin et al, 2001). Here, we investigate the impact of such fitness trade-offs on the evolution of insecticide resistance, through an assessement of the net effect of natural selection in relation to the nature of adaptive changes in Cydia pomonella populations. To do this, we follow changes in the frequencies of diflubenzuron-resistant phenotypes in a heterogeneous population under insecticide-free conditions for 10 generations. The magnitude of the fitness trade-offs associated with expression of two mutations involved in the same adaptive response is also explored at the biochemical scale, through the use of enhanced-MFO and -GST activities as phenotypic markers of resistance.

\section{Material and methods}

\section{Insects}

The field-derived susceptible (S) strain of C. pomonella has been mass reared continuously for 20 years in the absence of selection pressure on an artificial diet (Guennelon et al, 1981). The resistant strain (Rt) used in this study originated from a field population resistant to diflubenzuron. As a result of the low fertility of wild females, the hybrid Rt strain was produced by crossing males of the resistant population with $S$ females, resistance being already known to be autosomal and codominant in these populations (Sauphanor et al, 1998). The hybrid strain was selected by exposure to increasing concentrations of diflubenzuron that induced $50 \%$ mortality for the 10 first generations. Exposure of the 20 subsequent generations to a constant diagnostic dose of diflubenzuron (500 ppm) eliminated $100 \%$ of the susceptible individuals.

\section{Establishment of a heterogeneous population}

Generation $0\left(\mathrm{G}_{0}\right)$ was initiated by introducing 50 adult males and 50 adult females of each of the $S$ and Rt strains in a population cage, which was maintained under standard laboratory conditions $\left(25 \pm 1^{\circ} \mathrm{C}, 45 \pm 5 \% \mathrm{RH}\right.$, 16:8 h (L:D) photoperiod). An average random sample of 1500 neonates in the $G_{0}$ progeny was mass reared on an insecticide-free diet to constitute the following generation. The remaining larvae were fed on diet in individual plastic cups $\left(20 \times 20 \times 20 \mathrm{~mm}^{3}\right)$ for phenotypic frequency estimations through both toxicological and enzymatic approaches. This procedure was used over 10 generations. An estimate of the effective breeding size $N_{e}$ (Wright, 1938) reached in the population before estimating phenotypic frequencies was calculated as follows: $N_{e}=4\left(N_{m} N_{f}\right) /\left(N_{m}+N_{f}\right)$, with $N_{m}$ and $N_{f}$ being the numbers of males and females introduced in the population cage, respectively. The mean value of the $N_{e}$ estimate over the 10 generations was 973. This would prevent the occurrence of any genetic bottlenecks.

\section{Phenotypic characterization with standard toxicological tests}

At each generation, neonate larvae were tested with a 250-ppm concentration of diflubenzuron, previously spread on the diet of individual plastic cups. Although this concentration allowed a clear discrimination between susceptible and resistant phenotypes, distinction between heterozygotes and resistant homozygotes was not possible because the heterozygotes survived a 250-ppm concentration applied on the diet. The frequencies of the resistant phenotypes were thus inferred from survival percentages at $250 \mathrm{ppm}$ of diflubenzuron. Tests were conducted under standard laboratory conditions. Mortality was recorded after 7 days of exposure to diflubenzuron and corrected with that of controls treated with distilled water (Abbott, 1925).

\section{Phenotypic characterization with enzyme assays}

Enzyme assays were performed on 7-day-old larvae reared in individual plastic cups with diet under standard laboratory conditions without exposure to the insecticide. Cytochrome P450-dependent monooxygenase (MFO) activity. MFO activities were determined by measuring 7-ethoxycoumarin-O-deethylation (ECOD) (De Sousa et al, 1995). Each larva was cut into two fragments and introduced into individual microplate wells containing $100 \mu \mathrm{l}$ of $50 \mathrm{mM}$ sodium phosphate buffer ( $\mathrm{pH} 7.2$ ) and $0.4 \mathrm{mM}$ of ethoxycoumarin. The reaction was stopped after $4 \mathrm{~h}$ of incubation at $30^{\circ} \mathrm{C}$ by adding $100 \mu \mathrm{l}$ of glycine $\left(10^{-4} \mathrm{M}, \mathrm{pH} 10.4\right) /$ ethanol $(\mathrm{v} / \mathrm{v})$ buffer. Wells receiving glycine/ethanol buffer before incubation were used as control. Fluorescence was measured using a microplate reader (HTS 7000, PerkinElmer) with $380 \mathrm{~nm}$ excitation, $465 \mathrm{~nm}$ emission filters. Glutathione $S$-transferase (GST) activity. Each larva was homogenized on ice in $70 \mu \mathrm{l}$ of $50 \mathrm{mM}$ sodium phosphate buffer ( $\mathrm{pH}$ 7.2) containing $0.4 \mathrm{mM}$ final concentration of phenyl methyl sulphonyl fluoride. The homogenates were centrifuged at $4^{\circ} \mathrm{C}$ for $15 \mathrm{~min}$ at $15000 \mathrm{~g}$, and the supernatants were used as enzyme sources. Protein concentrations of the suspension were estimated by the method of Bradford (1976). The GST activity was determined on UV-microplates with 1-chloro-2,4-dinitrobenzene $(\mathrm{CDNB})$ as substrate. Each well contained $4 \mu \mathrm{l}$ of enzyme extract, $184 \mu \mathrm{l}$ of $50 \mathrm{mM}$ sodium phosphate buffer ( $\mathrm{pH} 7.2), 2 \mu \mathrm{l}$ of $0.1 \mathrm{M}$ reduced glutathione and $10 \mu \mathrm{l}$ of $30 \mathrm{mM}$ CDNB. Wells containing identical solutions added to $4 \mu \mathrm{l}$ of sodium phosphate buffer instead of the enzyme extracts were referenced as blanks. Optical density was recorded at $30^{\circ} \mathrm{C}$ for $1 \mathrm{~min}$ at $340 \mathrm{~nm}$.

Before the beginning of the experiment, measures of both GST and MFO activities were performed in the S, Rt and in the hybrid reciprocal F1 strains (SxRt and RtxS) to evaluate levels of enzyme expression.

\section{Analysis of the stability of resistance expression in the resistant $\mathrm{Rt}$ strain, in the absence of insecticide} Simultaneously with the population cage experiment described above, toxicological tests and measures of both GST and MFO activities were performed for seven generations in the absence of diflubenzuron in the Rt 
strain. This was done to assess whether fluctuations in biochemical markers in the heterogeneous population could be because of intrinsic fluctuations in enzyme expression in the absence of substrate rather than to a loss of resistance genes.

\section{Data analysis}

Variation among genotypes in GST and MFO expression was evaluated with an analysis of variance (ANOVA), as well as the effect of the seven generations on the values measured in the unselected Rt strain (Statview, SAS Institute Inc, USA, 1998). The mean enzymatic activities were compared among genotypes and generations with protected least significant difference (PLSD) Fisher tests. The hypothesis of a fitness cost of resistance assumes a selection coefficient which is applied against resistant phenotypes at each generation. Therefore, one would expect the frequency of the resistant phenotypes $\left(p_{\mathrm{R}}\right)$ to decrease logarithmically over $t$ generations as follows:

$$
p_{\mathrm{R}, t}=p_{\mathrm{R}, 0}(1-s)^{t}
$$

with $p_{\mathrm{R}, 0}$ being the initial frequency of the resistant phenotypes, and $s$ the fitness cost coefficient. An estimate of $s$ could thus be inferred from (1) as follows:

$$
s=1-\left[\left(p_{\mathrm{R}, t} / p_{\mathrm{R}, 0}\right)^{1 / t}\right]
$$

The assumption underlying (1) was tested using linear regressions performed on the log-transformations of both the toxicological and MFO data. The log-transformation procedure allowed the expression of (1) in the following form:

$$
\log \left(p_{\mathrm{R}, t}\right)=\log \left(p_{\mathrm{R}, 0}\right)+t \log (1-s)
$$

with $\log (1-s)$ being the slope of regression. Therefore, a covariance analysis (ANCOVA) of the linear regressions performed on the above log-transformations was used to evaluate the significance of any divergence in $s$ estimates between both toxicology and MFO production.

\section{Results}

\section{Evolution of resistant frequencies in the heterogeneous population}

There was evidence that the proportion of 250-ppmresistant phenotypes declined in the heterogeneous population. Initial frequencies dropped from 0.77 to 0.24 over 10 generations under insecticide-free conditions (Figure 1).

Enzymatic measures in the S, Rt, and F1 individuals show an overlapping of the range of activities between genotypes (Table 1). Even with lower overlapping for the MFOs, a phenotypic discrimination based on levels of activities could not be achieved. Therefore, MFO frequencies were statistically estimated. The MFO values were normally distributed (K. Pearson test, $P=0.1$ ). Thus, if the mean MFO activity $(m)$ of a given phenotype could take the values $m_{\mathrm{R}}$ (mean activity of the resistant phenotype) and $m_{\mathrm{S}}$ (mean activity of the susceptible phenotype) with probabilities $p_{\mathrm{R}}$ and $\left(1-p_{\mathrm{R}}\right)$, respectively, the mean MFO activity in the population at generation $t$ could be described as

$$
m_{t}=m_{\mathrm{R}} p_{\mathrm{R}, t}+m_{\mathrm{S}}\left(1-p_{\mathrm{R}, t}\right)
$$

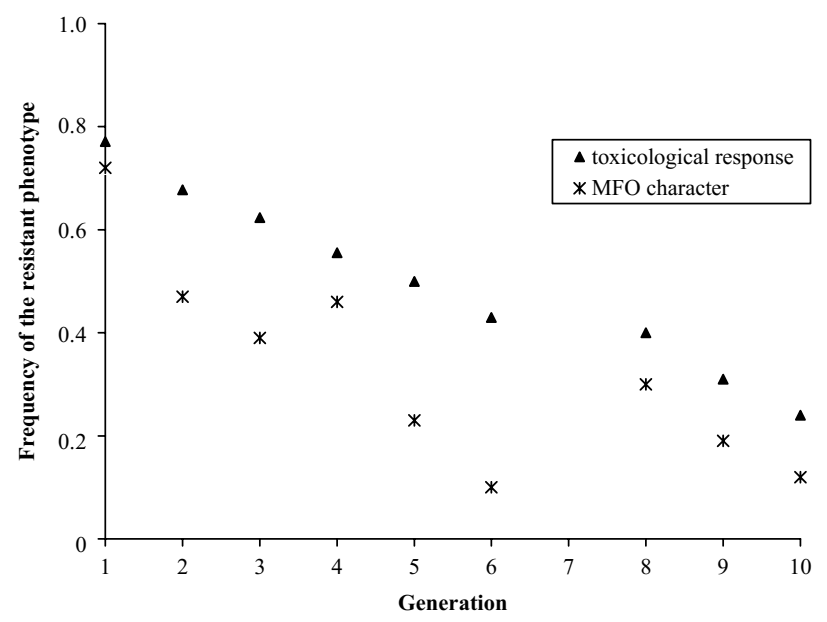

Figure 1 Frequencies of resistant phenotypes in a heterogeneous population of Cydia pomonella, held over 10 generations in the absence of insecticide selection. Phenotypic frequencies were inferred from toxicological tests using a diagnostic dose of insecticide, and estimation of metabolic activity of the cytochrome P450-dependent monooxygenase (MFO) character.

The frequency of the resistant phenotypes $p_{\mathrm{R}, t}$ was thereby estimated as

$$
p_{\mathrm{R}, t}=\left(m_{t}-m_{\mathrm{S}}\right) /\left(m_{\mathrm{R}}-m_{\mathrm{S}}\right)
$$

ANOVA performed on both GST and MFO assays showed that $S$ individuals expressed a mean activity statistically lower than that in the Rt and F1 individuals $(F=6.032, \mathrm{df}=2, \quad P<0.005$, and $F=251.254, \mathrm{df}=2$, $P<0.005$, respectively) (Table 1 ). The $m_{\mathrm{R}}$ parameter was therefore inferred from the mean MFO activity measured in both the Rt and F1 strains.

Estimated frequency of the MFO character $\left(p_{\mathrm{R}, t}\right)$ dropped from 0.72 to 0.12 over the 10 generations (Figure 1), as a result of a significant decrease in the mean MFO activity in the population (Table 2).

The significance levels of the linear regressions performed on both the log-transformed toxicological and MFO data supported the assumption of (1) $(r=0.97$, $P<0.01$, and $r=0.90, P<0.01$, respectively), that is, the decreasing trend of resistance frequencies for both toxicological responses and MFO production was probably owing to fitness costs (as referred to as $s$ ). The linear trend of the responses displayed in Figure 1 may be probably as a consequence of the fact that the time step of the experiment was not sufficiently large to observe an asymptotic behaviour of the frequency estimates, as expected in a logarithmic trend. Nevertheless, according to (2), $s$ values were estimated to be 0.11 and 0.17 for the toxicological responses and $\mathrm{MFO}$ production, respectively. According to (3), an ANCOVA analysis performed on the above linear regressions suggested that $s$ was significantly lower for the toxicological responses than MFO production $(F=100.763, \mathrm{df}=1, P<0.005)$.

Although the mean GST activity in the $S$ strain was significantly lower than that in the Rt and F1 strains (Table 1), the overlapping of the ranges of activities between genotypes was too extensive to use the method $\left(p_{\mathrm{R}, t}\right)$ described above. We thus only report the evolution of the mean GST activity in the population (Table 2). 
Table 1 Glutathione S-transferase (GST) (measured in $\mathrm{mg}$ of conjugate formed/mg protein/min) and cytochrome P450-dependent monooxygenase (MFO) (measured in pg of $7 \mathrm{OH}$ formed/larva/min) activities in homozygous susceptible (S/S), resistant (Rt/Rt), and reciprocal heterozygotes (S/Rt and Rt/S) of Cydia pomonella

\begin{tabular}{|c|c|c|c|c|}
\hline Enzyme & Genotype & Mean activity & Range of activity & Expression ratioc \\
\hline \multirow[t]{4}{*}{ GST } & $\mathrm{S} / \mathrm{S}$ & $1.05 \mathrm{a}$ & $0.11-2.23$ & 1 \\
\hline & $\mathrm{Rt} / \mathrm{Rt}$ & $1.45 \mathrm{~b}$ & $0.49-2.40$ & 1.38 \\
\hline & $\mathrm{S} / \mathrm{Rt}$ & $1.41 \mathrm{~b}$ & $0.59-2.51$ & 1.34 \\
\hline & $\mathrm{Rt} / \mathrm{S}$ & $1.58 \mathrm{~b}$ & $0.57-2.56$ & 1.5 \\
\hline \multirow[t]{4}{*}{ MFO } & $\mathrm{S} / \mathrm{S}$ & $16.27 a$ & $1.95-52.03$ & 1 \\
\hline & $\mathrm{Rt} / \mathrm{Rt}$ & $310.84 b$ & $121.72-570.16$ & 19.11 \\
\hline & $\mathrm{S} / \mathrm{Rt}$ & $82.98 c$ & $24.13-236.87$ & 5.1 \\
\hline & $\mathrm{Rt} / \mathrm{S}$ & $100.54 c$ & $28.12-259.07$ & 6.18 \\
\hline
\end{tabular}

For each enzyme, mean activities sharing the same letter do not differ statistically (protected least significant difference Fisher test, $P>0.05$ ). ${ }^{a}$ For each genotype, enzymatic tests were performed on 50 individuals. ${ }^{b}$ Lowest-highest values of the measured enzymatic activities. ${ }^{c}$ Mean activity of the genotype considered divided by the mean activity of the S/S genotype.

Table 2 Evolution of glutathione S-transferase (GST) (measured in $\mathrm{mg}$ of conjugate formed/mg protein/min) and cytochrome P450dependent monooxygenase (MFO) (measured in $\mathrm{pg}$ of $7 \mathrm{OH}$ formed/larva/min) activites in a heterogeneous population of $\mathrm{Cydia}$ pomonella, held for 10 generations in the absence of insecticide selection

\begin{tabular}{|c|c|c|c|c|c|c|}
\hline \multirow[t]{2}{*}{ Generation } & \multicolumn{3}{|c|}{ GST } & \multicolumn{3}{|c|}{$M F O$} \\
\hline & $n$ & Mean activity & $95 \% C I$ & $n$ & Mean activity & $95 \% C I$ \\
\hline 1 & 128 & $1.48 \mathrm{a}$ & $1.33-1.63$ & 149 & $122.89 a$ & $104.51-141.26$ \\
\hline 2 & 141 & $1.44 \mathrm{a}$ & $1.31-1.57$ & 140 & $85.92 b$ & $71.60-100.23$ \\
\hline 3 & 50 & $1.39 \mathrm{a}$ & $1.04-1.74$ & 150 & $74.82 \mathrm{~b}$ & $62.13-87.50$ \\
\hline 4 & 127 & $1.49 \mathrm{a}$ & $1.35-1.63$ & 133 & $84.56 \mathrm{~b}$ & 68.40-100.71 \\
\hline 5 & 84 & $1.59 \mathrm{a}$ & $1.36-1.82$ & 100 & $50.19 c$ & $40.08-60.30$ \\
\hline 6 & 66 & $1.45 \mathrm{a}$ & $1.16-1.74$ & 72 & $36.83 c$ & $25.83-47.82$ \\
\hline 8 & 95 & $1.45 \mathrm{a}$ & $1.26-1.64$ & 97 & $65.53 b$ & $50.84-80.21$ \\
\hline 9 & 87 & $1.49 \mathrm{a}$ & $1.27-1.71$ & 107 & $44.85 c$ & $40.14-49.56$ \\
\hline 10 & 90 & $1.48 \mathrm{a}$ & $1.28-1.68$ & 144 & $34.27 \mathrm{c}$ & $24.90-43.63$ \\
\hline
\end{tabular}

For each enzyme, mean activities sharing the same letter indicate the overlapping of their $95 \% \mathrm{CI}$.

Table 3 Evolution of glutathione S-transferase (measured in $\mathrm{mg}$ of conjugate formed $/ \mathrm{mg}$ protein/min) and cytochrome P450-dependent monooxygenase (MFO) (measured in $\mathrm{pg}$ of $7 \mathrm{OH}$ formed/larva/min) activities, and the toxicological response in a homozygous resistant (Rt) strain of Cydia pomonella, held for seven generations in the absence of insecticide selection

\begin{tabular}{|c|c|c|c|c|c|}
\hline \multirow[t]{2}{*}{ Generation } & \multicolumn{2}{|c|}{ GST } & \multicolumn{2}{|c|}{$M F O$} & \multirow{2}{*}{$\begin{array}{c}\text { Toxicological response } \\
(n=100)\end{array}$} \\
\hline & $n$ & Mean activity & $n$ & Mean activity & \\
\hline 1 & 50 & $1.45 a$ & 50 & $310.87 a$ & 100.00 \\
\hline 2 & 79 & $1.49 \mathrm{a}$ & 103 & $255.18 b$ & 100.00 \\
\hline 3 & 75 & $1.42 \mathrm{a}$ & 93 & $271.18 \mathrm{~b}$ & 99.00 \\
\hline 4 & 73 & $1.47 \mathrm{a}$ & 101 & $268.80 \mathrm{~b}$ & 99.31 \\
\hline 5 & 72 & $1.43 a$ & 102 & $269.47 b$ & 99.00 \\
\hline 6 & 77 & $1.41 \mathrm{a}$ & 103 & $270.47 \mathrm{~b}$ & 100.00 \\
\hline 7 & 73 & $1.42 \mathrm{a}$ & 101 & $269.58 b$ & 99.31 \\
\hline
\end{tabular}

For each enzyme, values sharing the same letter do not differ statistically (protected least significant difference Fisher test, $P>0.05$ ). aPercentage of survival at $250 \mathrm{ppm}$ of diflubenzuron, corrected by the control mortality.

Enhanced GST activity appeared to remain stable in the population over time (Table 2). However, the mean activity values remained higher than that measured in S/ $\mathrm{S}$ individuals (see Table 1$)(F=11.827, \mathrm{df}=1, P<0.005)$.

\section{Stability of resistance expression in the absence of insecticide substrate}

Relaxation of insecticide selection pressure over seven generations did not result in a decrease of resistance in the Rt strain, for both toxicological and enzymatic responses (Table 3). The slight variation in the mean GST activity among generations was not significant $(F=0.228, \mathrm{df}=6, P=0.9675)$. There was a significant decrease of the mean MFO activity from $G_{1}$ to $G_{2}$ $(F=12.675, \mathrm{df}=1, P<0.005)$, followed by stability of MFO production from $\mathrm{G}_{2}$ to $\mathrm{G}_{7} \quad(F=0.261, \mathrm{df}=5$, $P=0.9341$ ). The stability of the toxicological data suggests that such a decrease did not result in a change in the phenotypic response to diflubenzuron on the one 
hand (Table 3), and ensured homozygosity at the resistance loci in the Rt strain, on the other hand.

\section{Discussion}

Selection against resistance in the absence of insecticide Our results indicate that the frequency of diflubenzuronresistant phenotypes decreased over 10 generations in the absence of insecticide. The simultaneous use of biochemical markers of resistance indicated a discrepancy in the evolution of both cytochrome P450dependent monooxygenases (MFO) and glutathione $S$-transferases (GST) production; the former decreased while the latter remained stable over time under the same insecticide-free conditions. In insects, there is evidence that systems of detoxification such as MFO, GST, and carboxylesterases are inducible by the presence of various insecticides (Terriere, 1983; Feyereisen, 1999). To date, the role of induction mechanisms on enzyme expression still remains a black box in $C$. pomonella. Nevertheless, the relative stability of resistance expression over seven generations in the Rt strain without exposure of diflubenzuron, indicated that the absence of substrate did not alter the expression of modified enzymes in resistant phenotypes. Thus, the loss of the mean MFO activity in the heterogeneous population was a result of a reduction in frequency of the resistance alleles, rather than to a loss of enzyme expression.

Wright (1948) showed that random genetic drift and qualitative fluctuations of selection pressures influence the frequencies of alleles in populations. The decrease in the frequencies of resistant phenotypes in the absence of diflubenzuron may have been a result either of random genetic drift or selection against resistant phenotypes. The latter appear to be the better candidate to explain such a decrease of resistance frequencies. First, random genetic drift introduces stochasticity into changes in gene frequency (Wright, 1948; Uyenoyama, 1986), manifested as random oscillations of the frequency values over time. The statistical analysis of the evolution of the frequencies of diflubenzuron-resistant phenotypes and enhancedMFO indicated a progressive decrease of resistance frequencies. Second, pleiotropic costs associated with metabolic resistance to diflubenzuron were previously measured in the same strain of C. pomonella (Boivin et al, 2001), suggesting a selective disadvantage of the resistant phenotypes relative to the susceptible ones. Although we hypothesize that the decrease in resistance frequencies was the expression of a cost, we should point out that, because of the lack of replicate of the experiment, drift effects on resistance frequencies could not be formally precluded in the present work.

To date, manifestations of pleiotropic resistance costs have been well documented with respect to reproduction (Scott et al, 1997; Campanhola et al, 1991), development (Clarke and McKenzie, 1987) or behaviour (Rowland, 1991; Foster et al, 1999). Acquisition of streptomycin resistance in Escherichia coli was also shown to affect population growth, by reducing peptide chain elongation rates (Bilgin et al, 1992). Nevertheless, despite the abundance of fitness costs in the literature, it is critical to note that negative effects of resistance genes may not be necessarily large, and are not universal (Roush and McKenzie, 1987; McKenzie, 1993; Guillemaud et al, 1998). However, the results of this study, in agreement with other work (Chevillon et al, 1997; Guillemaud et al, 1998), suggests that different selective constraints may be associated with the two enzymatic systems involved in resistance in C. pomonella. The fitness cost associated with GST expression appeared to be negligible, because the mean activity measured in the heterogeneous population remained relatively stable over the 10 generations, yet significantly higher than that of the homozygous susceptible individuals. Conversely, the decrease of the frequency of enhanced-MFO phenotypes indicated a costly resistance mutation. Because the toxicological response paralleled that of the $\mathrm{MFO}$ character rather than that of GSTs, MFOs appeared to be the major mechanism involved in resistance to diflubenzuron. The GST system may account for resistance as a minor pathway, possibly through epistatic interactions with MFOs that contribute to the enhanced metabolization of the chemical (see Raymond et al, 1989). However, GSTbased resistance to organophosphates has been shown to involve high fitness costs in the housefly (Roush and Plapp, 1982), which suggests that the magnitude of the fitness costs associated with the acquisition of metabolic resistance might depend on the ratio of expression (relative to the susceptible reference) of the selected pathway.

In all fields of resistance, the expression of fitness costs are generally regarded as the consequence of biochemical and physiological perturbations (Roush and McKenzie, 1987; Bilgin et al, 1992; Purrington and Bergelson, 1996). Resistance mechanisms are thought to redirect the enzyme activity that is normally involved in metabolism towards detoxification. Cytochrome P450-dependent MFOs are involved in the metabolization of xenobiotics, but also play a role in the biosynthetic pathways of juvenile hormones and ecdysteroids, endogenous compounds regulating insect growth, development, and reproduction (Feyereisen, 1999). The phenotypic modifications involved in responses to environmental toxicity by generating high metabolization properties may thus interfere with their original function, constituting a physiological burden for mutants in the ancestral untreated environment. Metabolic resistances are also considered to be costly mechanisms, specifically with regard to the regulation mode of their expression (Uyenoyama, 1986; Soderlund, 1997).

\section{Pleiotropic costs and resistance management}

The cost of resistance is central to the study of the spread of resistance genes because of its impact on the relative fitness of carriers of such genes (Crow, 1957; May and Dobson, 1986). In this context, deleterious pleiotropic effects of resistance genes emphasize the benefits of the preventive use of nonchemical control methods, which may help to maintain low frequencies of resistance genes in the field. Reversion to susceptibility may be closely linked to the strength of resistance costs and to the rate of immigration of susceptible individuals into the treated area (Tabashnik and Croft, 1982; Carrière and Tabashnik, 2001). Lenormand and Raymond (1998) described a management model leading to the confinement of the resistance genes, by the use of fluctuating intensities of both gene flow and selection (for and against resistance). In south-eastern France apple orchards, the mean frequency of resistance was close to $75 \%$ according to 
recent field collections (Sauphanor et al, 2000). Given that two generations per year can successfully reproduce in this region, the present study suggested that more than 5 years of relaxation of diflubenzuron spraying would be required in order to result in an agronomically effective reversion of resistance in $C$. pomonella populations. We thus postulate that resistance management strategies exclusively based on insecticide alternations would not consistently delay the selection of resistance in this species, suggesting a need for alternative methods to chemical treatments. Although population cage experiments in the laboratory may confer the benefits of an inclusive approach of fitness (Minkoff and Wilson, 1992), the sustainable favourable development conditions allowed by such laboratory conditions may mitigate predictions based on extrapolation to field conditions. Metabolic resistances are known to induce severe deleterious effects in adverse conditions (Chevillon et al, 1997; Lenormand et al, 1999). Further work is therefore needed to ascertain the magnitude of such a selective disadvantage of resistance under natural conditions, which involve critical events of insect life cycles.

\section{Acknowledgements}

We thank Dr Denis Bourguet for critical comments. This work was supported by Le Conseil Régional ProvenceAlpes-Côte d'Azur, France.

\section{References}

Abbott WS (1925). A method of computing the effectiveness of an insecticide. J Econ Entomol 18: 265-267.

Amin AM, White GB (1984). Relative fitness of organophosphate-resistant and susceptible strains of Culex quinquefasciatus Say (Diptera: Culicidae). Bull Entomol Res 74: 591-598.

Bilgin N, Claesens F, Pahwerk H, Ehrenberg, M (1992). Kinetic properties of Escherichia coli ribosomes with altered forms of S12. J Mol Biol 224: 1011-1027.

Boivin T, Chabert-d'Hières C, Bouvier JC, Beslay D, Sauphanor B (2001). Pleiotropy of insecticide resistance in the codling moth, Cydia pomonella. Ent Exp Appl 99: 381-386.

Bradford MM (1976). A rapid and sensitive method for the quantification of microgram quantities of proteins utilizing the principle of protein-dye binding. Ann Biochem 72: 248254.

Campanhola C, McCutchen BF, Baehrecke EH, Plapp Jr FW (1991). Biological constraints associated with resistance to pyrethroids in the tobacco budworm (Lepidoptera: Noctuidae). J Econ Entomol 84: 1404-1411.

Carrière Y, Tabashnik BE (2001). Reversing insect adaptation to transgenic plants. Proc $R$ Soc Lond B 268: 1475-1480.

Carrière Y, Deland JP, Roff DA, Vincent C (1994). Life-history costs associated with the evolution of insecticide resistance. Proc R Soc Lond B 258: 35-40.

Chevillon C Bourguet D Rousset F Pasteur N Raymond M (1997). Pleiotropy of adaptative changes in populations: comparisons among insecticide resistance genes in Culex pipiens. Genet Res Camb 70: 195-204.

Clarke GM McKenzie JA (1987). Developmental stability of insecticide resistant phenotypes in blowfly; a result of canalising natural selection. Nature 325: 345-346.

Coustau C, Chevillon C, Ffrench-Constant R (2001). Resistance to xenobiotics and parasites: can we count the cost? Trends Ecol Evol 9: 378-383.
Crow JF (1957). Genetics of insect resistance to chemicals. Ann Rev Entomol 2: 227-246.

Curtis CF, Cook LM, Wood RJ (1978). Selection for and against insecticide resistance and possible methods of inhibiting the evolution of resistance in mosquitoes. Ecol Entomol 3: 273287.

De Sousa G, Cuany A, Brun A, Amichot M, Rahmani R, Bergé JB (1995). A microfluorometric method for measuring etoxycoumarin-O-deethylase activity on individual Drosophila melanogaster abdomens: interest for screening resistance in insect populations. Anal Biochem 229: 86-91.

Feyereisen R (1999). Insect P450 enzymes. Annu Rev Entomol 44: 507-533.

Fisher RA (1958). The Genetical Theory of Natural Selection, 2nd edn, New York: Dover.

Foster SP, Woodcock CM, Williamson MS, Devonshire AL, Denholm I, Thompson R (1999). Reduced alarm response by peach-potato aphids, Myzus persicae (Hemiptera: Aphididae), with knock-down resistance to insecticides $(k d r)$ may impose a fitness cost through increased vulnerability to natural enemies. Bull Entomol Res 89: 133-138.

Guennelon G, Audemard H, Fremond JC, Idrissi Ammari AM (1981). Progrès réalisés dans l'élevage du carpocapse (Laspeyresia pomonella L.) sur milieu artificiel. Agronomie 1: 59-64.

Guillemaud T, Lenormand T, Bourguet D, Chevillon C, Pasteur $\mathrm{N}$, Raymond M (1998). Evolution of resistance in Culex pipiens: allele replacement and changing environment. Evolution 52: 443-453.

Holloway GJ, Povey SR, Sibly RM (1990). The effect of new environment on adapted genetic architecture. Heredity 64: 323-330.

Lenormand T, Raymond M (1998). Resistance management: the stable zone strategy. Proc R Soc Lond B 265: 1985-1990.

Lenormand T, Bourguet D, Guillemaud T, Raymond M (1999). Tracking the evolution of insecticide resistance in the mosquito Culex pipiens. Nature 400: 861-864.

May RM, Dobson AP. (1986). Population dynamics and the rate of evolution of insecticide resistance. In: Committee on strategies for the management of pesticide resistant pest populations. Pesticide Resistance; Strategies and Tactics for Management, National Academy Press: Washington, DC, pp 170-193.

McKenzie JA (1993). Measuring fitness and intergenic interactions: the evolution of resistance to diazinon in Lucilia cuprina. Genetica 90: 227-237.

McKenzie JA, Batterham P (1994). The genetic, molecular and phenotypic consequences of selection for insecticide resistance. Trends Ecol Evol 9: 166-169.

McNair MR (1991). Why the evolution of resistance to anthropogenic toxins normally involves major gene changes: the limits to natural selection. Genetica 84: 213-219.

Minkoff III C, Wilson TG (1992). The competitive ability and fitness components of the methoprene-tolerant (Met) Drosophila mutant resistant to juvenile hormone analog insecticides. Genetics 131: 91-97.

Purrington CB, Bergelson J (1996). Surveying the patterns in the cost of resistance in plants. Am Nat 148: 536-558.

Raymond M, Heckel DG, Scott JG (1989). Interactions between pesticide genes: model and experiment. Genetics 123: 543-551.

Roush RT, McKenzie JA (1987). Ecological genetics of insecticide and acaricide resistance. Ann Rev Entomol 32: 361-380.

Roush RT, Plapp Jr FW (1982). Effects of insecticide resistance on biotic potential of the house fly (Diptera: Muscidae). J Econ Entomol 75: 708-713.

Rowland M (1991). Behaviour and fitness of $\gamma \mathrm{HCN} /$ dieldrin resistant and susceptible female Anopheles gambiae and An. stefensi mosquitoes in the absence of insecticide. Med Vet Entomol 5: 193-206.

Sauphanor B, Brosse V, Bouvier JC, Speich P, Micou A, Martinet C (2000). Monitoring resistance to diflubenzuron and 
deltamethrin in French codling moth populations (Cydia pomonella). Pest Manag Sci 56: 1-9.

Sauphanor B, Bouvier JC, Brosse V (1998). Spectrum of insecticide resistance in Cydia pomonella (Lepidoptera: Tortricidae) in southeastern France. J Econ Entomol 91: 1225-1231.

Sauphanor B, Cuany A, Bouvier JC, Brosse V, Amichot M, Bergé JB (1997). Mechanisms of resistance to deltamethrin in Cydia pomonella (L.) (Lepidoptera: Tortricidae). Pestic Biochem Physiol 58: 109-117.

Scott M Diwell K McKenzie JA (2000). Dieldrin resistance in Lucilia cuprina (the Australian sheep blow fly): chance, selection and response. Heredity 84: 599-604.

Scott JA, Plapp Jr FW, Bay DE (1997). Pyrethroid resistance associated with decreased biotic fitness in horn flies (Diptera: Muscidae). South Entomol 22: 405-410.

Soderlund DM (1997). Molecular mechanisms of insecticide resistance. In: Sjut V (ed) Molecular Mechanisms of Resistance to Agrochemicals, Springer: Berlin, pp 21-56.

Tabashnik BE, Croft BA (1982). Managing pesticide resistance in crop-arthropod complexes: integrations between biological and operational factors. J Econ Entomol 11: 11371144.

Terriere LC. (1983). Enzyme induction, gene amplification and insect resistance to insecticides. In: Georghiou GP, Saito T (eds) Pest Resistance to Pesticides. Plenum: New York, pp 265298.

Tienderen PH van (1997). Generalists, specialists, and the evolution of phenotypic plasticity in sympatric populations of distinct species. Evolution 51: 1372-1380.

Uyenoyama MK (1986). Pleiotropy and the evolution of genetic systems conferring resistance to pesticides. In: Committee on strategies for the management of pesticide resistant pest populations. Pesticide Resistance: Strategies and Tactics for Management, National Academy Press: Washington, DC. pp 207-221.

Wright S (1938). Size of populations and breeding structure in relation to evolution. Science 87: 430-431.

Wright S (1948). On the roles of directed and random changes in gene frequency in the genetics of populations. Evolution 2: 279-294. 